\title{
Medication errors: the human factor
}

\author{
Edward Etchells MD MSc, David Juurlink MD PhD, Wendy Levinson MD
}

$\infty$

See related article page 42

I $\mathrm{n}$ this issue, Parshuram and colleagues describe a study that included II 8 health care professionals who prepared 464 morphine infusions under simulated conditions with direct observation. ${ }^{1}$ The morphine concentration in each prepared infusion was measured using chromatography. They report that $34.7 \%$ of infusions deviated from the intended concentration by more than $10 \%$. In addition, they found that $3 \%$ of drug-volume calculations had 2 -fold errors and I.2\% had Io-fold errors. This study supports previous findings of high error rates in the preparation of intravenous medications.

The high error rate for intravenous narcotic preparations should come as no surprise. The immutable reality is that humans make mistakes. Patients will be safer when we accept this reality and design clinical tasks accordingly. Medication errors pervade all phases of acute care. About $20 \%$ of patients will have a potentially harmful error in their preadmission medication history that may result in an incorrect medication order at the time of admission. ${ }^{2}$ During admission to hospital, the error rate for drug prescribing is at least $3 \%,{ }^{3,4}$ and, based on direct observation, the error rate in drug administration is about $19 \% .^{5}$ There is a $2 \%$ error rate for intravenous infusions in critical care. ${ }^{6}$ Upon discharge, about $25 \%$ of patients will have an error in their discharge prescriptions compared with their hospital medications. ${ }^{7}$ Although these studies used different methods and measures and included different patient populations, their collective message is that the likelihood of having a hospital admission free of medication error is vanishingly small.

Despite the frequency of these medication errors, most cause no harm to patients. The most common error is delayed drug administration resulting from a missing dose. More serious medication errors have a greater potential for harm and can be termed "potential adverse drug events." For example, a ro-fold error in morphine concentration is obviously more serious than a 10\% error. Medication errors that actually cause harm are termed "preventable adverse drug events." For every Ioo medication errors, there are between 4 and Io potential adverse drug events and I preventable adverse drug event. ${ }^{8}$ Depending on methods and definitions, about $\mathrm{I} \%-2 \%$ of patients will experience a preventable adverse drug event while in hospital. ${ }^{9}$

There are 2 potential approaches to reducing medication error. The "person-centred approach" focuses on the individual who makes the error. This individual may receive education, training or possibly discipline if the error was serious (e.g., a ro-fold morphine overdose). The person-centred approach is doomed to fail, however, because errors are an
Key points of the article
- Medication errors are common.
- The system-centred approach to medication error is based on 3 principles: error is unavoidable; processes can be designed to reduce the possibility of error; and processes can be designed so that errors are detected and corrected before harm occurs.
- Forcing functions, simplification and standardization are useful safety-improvement concepts.

inherent property of the people doing the work and the complexity of the work itself, as demonstrated by Parshuram and many others. ${ }^{1}$ By contrast, the "system-centred approach" is based on 3 principles: $:^{10}$ error is unavoidable; processes can be designed to reduce the possibility of error; and processes can be designed so that errors are detected and corrected before harm occurs.

Many strategies can reduce the possibility of error. "Forcing functions" are safety design features that completely eliminate the possibility of a specific error. In the study by Parshuram and colleagues, the use of a concentrated morphine solution (Io $\mathrm{mg} / \mathrm{mL}$ ) was strongly associated with serious errors (2- and Io-fold errors). ${ }^{1}$ One potential forcing function would be to remove $10 \mathrm{mg} / \mathrm{mL}$ morphine solutions from pediatric areas and to use $2 \mathrm{mg} / \mathrm{mL}$ solutions exclusively. This simple manoeuvre would not change the rate of error, but it would change the rate of serious error. The Institute for Safe Medication Practice recommends the removal of Io $\mathrm{mg} / \mathrm{mL}$ morphine solutions from pediatric care areas. ${ }^{11}$ Despite this recommendation, a 2004/05 survey found that up to $25 \%$ of pediatric care centres in Ontario continue to stock the concentrated solution. ${ }^{11}$

Simplification is another valuable safety improvement method. Calculators strategically placed in preparation areas for intravenous narcotics will simplify the task and eliminate the potential for error that results from mental arithmetic. Standardization can also reduce the potential for error. ${ }^{12}$ For example, hospitals can limit the number of intravenous morphine solutions and require these solutions to be prepared centrally in the pharmacy, rather than ward staff preparing numerous infusion concentrations.

Safety improvements can entail additional costs and complexities. ${ }^{13}$ In general, forcing-function strategies that involve

From the Department of Medicine (Etchells, Juurlink, Levinson), University of Toronto; and the Sunnybrook Health Sciences Centre (Etchells, Juurlink), Toronto, Ont. 
hazard removal (e.g., elimination of concentrated narcotics) are cheaper and less complex than major system changes (e.g., computerized physician order entry). However, unintended downsides can occur with all safety improvements. For example, the removal of concentrated potassium chloride solutions without appropriate replacement solutions could lead to inappropriate hoarding of the concentrated solution by staff, ${ }^{14}$ and poor design and implementation of systems for computerized physician order entry can increase error. ${ }^{15}$

Medication errors are unavoidable, but attention to safety improvement principles can reduce harm. The study by Parshuram and colleagues provides further empirical data that should spur us to action. We must continue to focus our attention on systematically applying and evaluating safety improvements, rather than demanding perfection from individual health care professionals.

Competing interests: None declared.

Contributors: All of the authors contributed to the conception and design of the manuscript, drafted the article and revised it critically for important intellectual content. All of the authors approved the final version for publication.

\section{REFERENCES}

I. Parshuram CS, To T, Seto W, et al. Systematic evaluation of errors occurring during the preparation of intravenous medication. $C M A J$ 2008;178:42-8.

2. Tam VC, Knowles SR, Cornish PL, et al. Frequency, type and clinical importance of medication history errors at admission to hospital: a systematic review. $C M A J$
2005;173:510-5.

3. Lesar TS, Briceland LL, Delcoure K, et al. Medication prescribing errors in a teaching hospital. JAMA I990;263:2329-34.

4. Bobb A, Gleason K, Husch M, et al. The epidemiology of prescribing errors: The potential impact of computerized prescriber order entry. Arch Intern Med 2004; I64:785-92.

5. Barker KN, Flynn EA, Pepper GA, et al. Medication errors observed in 36 health care facilities. Arch Intern Med 2002;162:I897-903.

6. Rothschild JM, Keohane CA, Cook EF, et al. A controlled trial of smart infusion pumps to improve medication safety in critically ill patients. Crit Care Med 2005; 33:533-40.

7. Schnipper JL, Kirwin JL, Cotugno MC, et al. Role of pharmacist counseling in preventing adverse drug events after hospitalization. Arch Intern Med. 2006;166:565-7I.

8. Bates DW, Boyle DL, Vander Vliet MB, et al. Relationship between medication errors and adverse drug events. J Gen Intern Med I995;10:199-205.

9. Kanjanarat P, Winterstein AG, Johns TE, et al. Nature of preventable adverse drug events in hospitals: a literature review. Am J Health Syst Pharm 2003;60:1750-9.

Io. Reason J. Human error: models and management. BMJ 2000;320:768-70.

II. Institute for Safe Medication Practices Canada. Medication safety support service acute care system safeguards to prevent error induced injury with narcotics (opioids): analysis for Ontario hospitals. Toronto: The Institute; 2007.

I2. Shah AN, Frush K, Luo X, et al. Effect of an intervention standardization system on pediatric dosing and equipment size determination: a crossover trial involving simulated resuscitation events. Arch Pediatr Adolesc Med 2003;157:229-36.

I3. Agency for Healthcare Research and Quality. Making health care safer: a critical analysis of patient safety practices. Evidence report/technology assessment (no. 43, AHRQ publication no. oI-E058). Rockville (MD): The Agency; 200I. Available: www.ahrq.gov/clinic/ptsafety/ (accessed 2007 Nov I3).

I4. Shojania KG, Duncan WD, McDonald KM, et al. Safe but sound: patient safety meets evidence-based medicine. JAMA 2002;288:508-13

I5. Ammenwerth E, Talmon J, Ash JS, et al. Impact of CPOE on mortality rates - contradictory findings, important messages. Methods Inf Med 2006;45:586-93.

Correspondence to: Dr. Wendy Levinson, Department of Medicine, University of Toronto, 3-805, Igo Elizabeth St., Toronto ON M5G 2C4; fax 4I6 978-7230; wendy.levinson@utoronto.ca

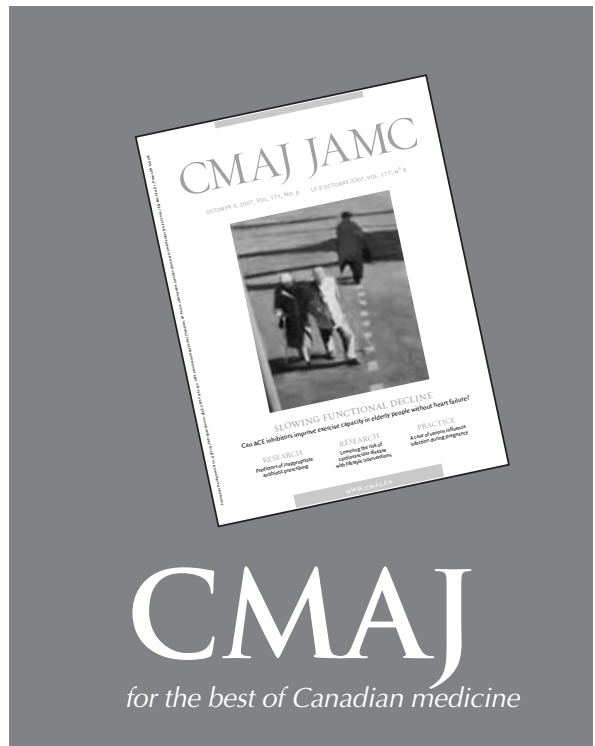

3000 volunteer reviewers from around the world are the foundation for CMAJ's thorough, criteriabased review process. The editorial staff includes scientific consultants with expertise in statistics, experimental design and epidemiology.

For subscription information, contact

CMA Member Service Centre

tel $888855-2555$ or $613731-8610 \times 2307$

fax $613236-8864$

cmamsc@cma.ca

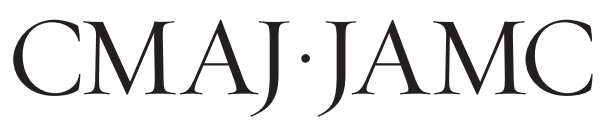

